\title{
ANATOMIA E ARTE DO MESTRE ALEIJADINHO: UMA FERRAMENTA METODOLÓGICA PARA O ENSINO DE ANATOMIA HUMANA
}

\author{
Luiz Eduardo Sousa ${ }^{1}$ \\ Thiago Rodrigues Araújo Cunha
}

SOUSA, L. E.; CUNHA, T. R. A. Anatomia e arte do mestre Aleijadinho: uma ferramenta metodológica para o ensino de anatomia humana. EDUCERE - Revista da Educação, Umuarama, v. 17, n. 1, p. 65-78, jan./ jun. 2017.

RESUMO: Considerado um dos grandes artistas do barroco brasileiro, Antônio Francisco Lisboa, também conhecido popularmente pela alcunha de Aleijadinho, foi um dos maiores artistas do barroco luso-brasileiro, nascido na cidade histórica de Ouro Preto - MG no século XVIII. Aleijadinho presenciou o apogeu da exploração aurífera nas Minas Gerais e o declínio dos grandes aluviões, participando do ápice e da derrocada da primeira civilização urbana do Brasil, à qual mediante a pujante economia serviu em dourado as obras feitas pelo artista. Este trabalho objetiva constatar a notória evolução técnica em relação aos detalhes anatômicos de suas esculturas humanas, especialmente nas obras da quinta fase (Máxima) correlacionando os aspectos de suas esculturas com atlas anatômicos atuais.

PALAVRAS-CHAVE: Anatomia; Artes; Barroco; Esculturas.

\section{ANATOMY AND ART OF ALEIJADINHO: A METHODOLOGICAL TOOL FOR HUMAN ANATOMY EDUCATION}

ABSTRACT: Considered one of the great artists of the Brazilian Baro-

DOI: https://doi.org/10.25110/educere.v17i1.2017.6284

${ }^{1}$ Universidade Federal de Ouro Preto, Departamento de Ciências Biológicas; Fisioterapeuta, Professor de Anatomia Humana do Departamento de Ciências Biológicas. Mestre em Saúde e Doutor em Ciências Biológicas. E-mail: luizeduardo@iceb.ufop.br

${ }^{2}$ Universidade Federal de Ouro Preto, Departamento de Ciências Biológicas; Acadêmico do curso de Nutrição da Universidade Federal de Ouro Preto. Monitor de Anatomia Humana do Departamento de Ciências Biológicas. E-mail: glicopan@gmail.com 
que, Antonio Francisco Lisboa, also popularly known by the nickname of Aleijadinho, he was one of the greatest artists of the Luso-Brazilian Baroque, born in the historic city of Ouro Preto - MG in the eighteenth century. Aleijadinho witnessed the heyday of gold exploration in Minas Gerais and the decline of large alluvial deposits, participating in the summit and the collapse of the first urban civilization of Brazil, which by the strong economy served in golden works done by the artist. This study aims to establish the notorious technical developments in relation to the anatomical details of his human sculptures, especially in the works of the fifth phase (Maximum) correlating aspects of his sculptures with current anatomical atlas.

KEYWORDS: Anatomy; Arts; Baroque; Sculptures.

\section{ANATOMÍA Y ARTE DEL ARTISTA BARROCO ALEIJADINHO: UNA HERRAMIENTA METODOLÓGICA PARA LA ENSEÑANZA DE ANATOMÍA HUMANA}

RESUMEN: Considerado uno de los grandes artistas del barroco brasileño, Antonio Francisco Lisboa, también conocido popularmente con el sobrenombre de Aleijadinho, fue uno de los más grandes artistas del barroco luso brasileño, nacido en la ciudad histórica de Ouro Preto - MG en el siglo XVIII. Aleijadinho fue testigo del auge de la exploración del oro en Minas Gerais y el declino de los grandes depósitos aluviales, participando del ápice y de la derrocada de la primera civilización urbana de Brasil, a la cual delante de la economía fuerte sirvió oro en las obras realizadas por el artista. Este estudio tiene por objeto constatar la notoria evolución técnica en relación a los detalles anatómicos de sus esculturas humanas, sobre todo en las obras de la quinta fase (Máxima) correlacionando los aspectos de sus esculturas con atlas anatómicos actuales.

PALABRAS CLAVE: Anatomía; Artes; Barroco; Esculturas.

\section{INTRODUÇÃO}

Com uma vida repleta de controvérsias, mesmo sendo um dos personagens da história brasileira mais biografados, Antônio Francisco Lisboa popularmente conhecido como Aleijadinho, foi um dos maiores artistas do barroco luso-brasileiro, nascido na cidade histórica de Ouro 
Preto - MG no século XVIII (a data exata de nascimento é incerta, por volta de 1738), filho do mestre-arquiteto português Manuel Francisco Lisboa, natural de Lisboa, e da escrava Isabel (TEIXEIRA, 2007; JARDIM et al, 2011). Em meados de 1750, Aleijadinho frequentou o Seminário dos Franciscanos Donatos do Hospício da Terra Santa, até aproximadamente 1762, em Ouro Preto. Nesse período, ele frequentou os estaleiros das obras de seu pai, trabalhando também com seu tio, o entalhador Antônio Francisco Pombal. Em 1759, deixa o hospício da Terra Santa e ocupa-se no aprendizado e do lançamento em tempo integral na profissão de marceneiro, entalhador, escultor e arquiteto (TEIXEIRA, 2007; JARDIM et al., 2011; MUSEU ALEIJADINHO, 2016).

Nos anos de 1770, dada a importância crescente de seu ateliê, passa a contratar diretamente as suas empreitadas, recebendo uma alta remuneração pelos seus projetos. O período entre 1777 e 1780 foi o provável início de uma doença degenerativa nos membros, sobretudo nas mãos o que alterou profundamente sua forma de trabalhar. Entre os anos de 1812 e 1813 o estado de saúde de Aleijadinho agrava-se e as capacidades motoras ficam quase nulas (MUSEU ALEIJADINHO, 2016).

O estilo artístico de Aleijadinho foi herdado de seu pai, de André Ribeiro Soares da Silva e Antônio Monteiro de Braga. Em Minas Gerais Aleijadinho conviveu, até os 21 anos, com Francisco Xavier de Brito e José Coelho de Noronha, mestres dos quais aprendeu o estilo caprichoso e detalhista do panejamento e dos cabelos. O "estilo Aleijadinho" desenvolveu-se ao longo da vida, com mais de 50 anos de carreira profissional, e especialmente por essa razão foi-se modificando ao longo do tempo. Sua obra pode ser classificada em cinco fases, em ordem cronológica: Mocidade, Maturidade Inicial, Maturidade Média, Maturidade Plena e Máxima(JARDIM et al., 2011).

Tendo vivido entre o apogeu da exploração aurífera nas Minas Gerais e o esgotamento dos grandes aluviões, o artista participa do fausto e da decadência da primeira civilização urbana do Brasil, a qual oferece, como legenda, o fulgor de seu talento singular, quando por exemplo é escalado para esculpir obras na primeira capital mineira. É ele fruto de um processo socioeconômico e cultural que, como seu fenômeno existencial, parte da glória para penoso declínio, do prazer da fortuna para a angústia da perda, mas também da sujeição para a busca da liberdade, da condição 
colonial para a independência (DE CASTRO MAIA, 2009).

Ao observar diferentes obras do mestre Aleijadinho, pode-se constatar notória evolução técnica em relação aos detalhes anatômicos de suas esculturas humanas, especialmente nas obras da quinta fase (Máxima). O presente trabalho vislumbra o uso de obras do artista no ensino de anatomia, buscando uma fortuita pedagógica que estimule o aprendizado da disciplina de Anatomia Humana. Para tal, analisamos do ponto de vista anatômico a obra "Anjo da Agonia", assegurando sua aplicabilidade no ensino acadêmico. O ensino de Anatomia Humana para os cursos de ciências médicas necessita dos melhores métodos pedagógicos devido à real necessidade desse conhecimento na atividade profissional (FRAHER et al., 2009). O uso de cadáveres vem sendo usado há séculos nas aulas de anatomia, entretanto podemos nos deparar com a necessidade de modernizar e diversificar a metodologia de ensino objetivando uma melhor formação acadêmica (ESTAI et al., 2009; PONTINHA et al., 2014).

O presente estudo tem como objetivo analisar o detalhamento anatômico expresso na escultura "Anjo da Agonia", obra realizada na fase Máxima do mestre Aleijadinho e, certificar a possibilidade do uso da imagem analisada como ferramenta metodológica no ensino de Anatomia Humana.

\section{MÉTODOS E MATERIAIS}

Buscando corroborar as ideias de que ensino, arte e anatomia são ramos de conhecimentos interligados, este trabalho visa por meio de uma revisão bibliográfica e análise comparativa da imagem do "Anjo da Agonia" (Figura 1) com as ilustrações de atlas tradicionais de Anatomia Humana (NETTER, 2011; SOBOTTA, 2012) estabelecer uma ligação entre as obras barrocas do artista luso brasileiros, denotando que este possuía conhecimentos sobre anatomia de superfície para a construção de suas obras. A análise foi realizada por meio de uma fotografia de alta qualidade da obra "Anjo da Agonia" publicada por Márcio Jardim et al. (2011). Foram pesquisadas as estruturas da morfologia externa do corpo humano, como relevos e depressões, com destaque às estruturas dos sistemas muscular, esquelético e articular. A obra em questão foi escolhida devido ao corpo parcialmente despido, expondo uma forma atlética e anatomica- 
mente detalhada.

Figura 1: Fotografia do "Anjo da Agonia" (JARDIM et al., 2011 p. 162). Escultura em cedro, policromada, 1,70 metros de altura. Representação da região ventral de um corpo jovem, magro e anatomicamente perfeito.

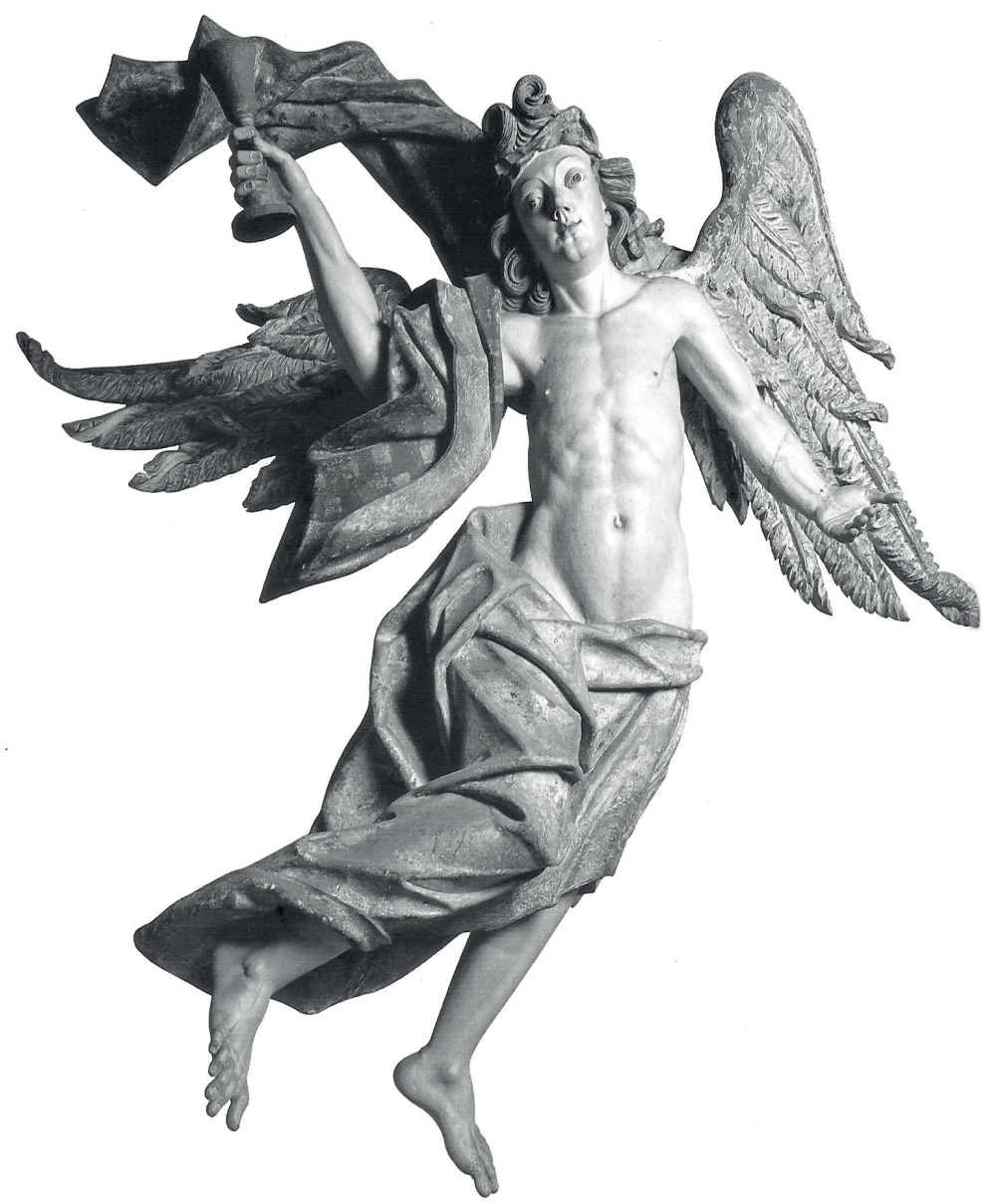

O "Anjo da Agonia" está exposto ao público no Santuário de Bom Jesus de Matosinhos, município de Congonhas - MG. Atualmente o Santuário é Patrimônio Mundial pela UNESCO(UNESCO, 2016). 


\section{RESULTADOS}

A análise da obra resultou na identificação de mais de 30 regiões reconhecidas anatomicamente. Em todas elas encontramos fidelidade anatômica, ao mesmo tempo com traços artísticos característicos do Aleijadinho. Todas as estruturas encontradas estavam localizadas apenas na região ventral do corpo.

Realizando análise da face da obra "Anjo da Agonia" (figura 2), percebe-se nitidamente a sua constante estilística com o posicionamento dos olhos afastados, com sobrancelhas mais finas e arqueadas assim como nariz fino e proeminente. Notam-se também ossos zigomáticos elevados, mas não tão pronunciados como observado em outras de suas esculturas. Outros aspectos morfológicos que se destacam são o filtro do lábio superior profundo e o queixo proeminente. Na região cervical, os músculos esternocleidomastóideos estão salientes, bem como o contorno do músculo trapézio esquerdo. As comparações anatômicas foram com atlas de Anatomia Humana (NETTER, 2011; SOBOTTA, 20112).

O tronco do "Anjo da Agonia" (Figura 2) apresenta grande detalhamento de músculos e ossos, evidenciando um corpo atlético com baixa quantidade de tecido adiposo subcutâneo. As clavículas estão com o posicionamento correto de acordo o posicionamento dos membros superiores. No tórax, a região esternal (região do osso esterno) mostra a inserção do músculo peitoral maior, deixando bem claro a formação de feixes musculares mais salientes. Na região infraesternal, fica claro a preocupação do artista em evidenciar o pequeno processo xifoide. Outro músculo que está em destaque é o serrátil anterior, pois se pode observar o relevo dos seus ventres musculares de aspecto serrilhado na face lateral esquerda do tórax. As observações estão de acordo com a literatura científica (NETTER, 2011; SOBOTTA, 20112).

$\mathrm{Na}$ região da axila esquerda (Figura 2) existe a marca da prega axilar anterior, formada pelo músculo peitoral maior. No lado esquerdo, o músculo peitoral maior segue até o úmero (osso do braço), passando, posteriormente, ao músculo deltoide, o que está anatomicamente correto (NETTER, 2011; SOBOTTA, 20112). Na região inferior das costelas, está bem saliente o ângulo infraesternal (subcostal) e as margens costais, possivelmente o artista também quis realçar as inserções dos músculos do 
abdome nessas regiões, devido ao aspecto robusto dessas margens (NETTER, 2011; SOBOTTA, 20112).

No abdome (Figura 2), alguns aspectos se destacam como a impressão da linha alba (dividindo superficialmente o abdome em metade direita e esquerda) e os ventres do músculo reto do abdome. O posicionamento da cicatriz umbilical está correto, alinhado próximo às margens superiores das cristas ilíacas (NETTER, 2011; SOBOTTA, 20112).

Nos membros inferiores (Figura 2) o artista buscou salientar aspectos importantes da anatomia. Na região próximal alguns músculos se destacam, como o tensor da fáscia lata e glúteo médio. O maléolo lateral (pertencente à fíbula) do membro inferior direito está evidente, com destaque para o detalhe dos tendões dos músculos fibulares, passando, posteriormente ao maléolo. No dorso do pé direito, estão presentes as marcas dos tendões dos músculos extensores dos dedos. No membro inferior esquerdo, na perna encontra-se a marca da margem anterior da tíbia terminando distalmente no maléolo medial. Nota-se também uma pequena prega sobre o osso calcâneo, o que indica a posição relaxada dos músculos gastrocnêmio e sóleo, pois o tendão do calcâneo também não está em destaque. Há também a presença dos arcos dos pés e os dedos estão com as características do artista, ou seja, dedos finos e alongados (NETTER, 2011; SOBOTTA, 20112).

Nos membros superiores (Figura 2), o artista destacou corretamente os músculos do antebraço, especialmente no membro direito. $\mathrm{O}$ membro que segura o Cálice da Amargura apresenta os músculos flexores do carpo e dedos mais salientes, o que indica que estão em estado de contração muscular. O antebraço está em posição semipronado (levemente rodado), com destaque para os músculos extensores do carpo e dos dedos. Na mão direita, o $5^{\circ}$ dedo ("dedo mínimo") encontra-se levemente rodado para dentro da mão, em relação aos outros dedos, indicando a oposição do dedo. No membro superior esquerdo, o contorno e relevo de músculos como deltoide, bíceps braquial e os tendões dos flexores do carpo estão em destaque. Na região medial do braço, a presença de uma linha pode indicar a intenção do artista em destacar os vasos e nervos (vasos braquiais) que se localizam nessa região (NETTER, 2011; SOBOTTA, 20112). 
Figura 2: Estruturas anatômicas identificadas na região ventral do corpo do "Anjo da Agonia" (adaptado de JARDIM et al.,2011 p. 162-163). a arco superciliar; b - pálpebra superior; c - osso zigomático; d - asa do nariz; e - filtro do lábio superior; $\mathrm{f}$ - proeminência mentual; $\mathrm{g}$ - músculo esternocleidomastoide; $\mathrm{h}$ - clavícula; $\mathrm{i}$ - prega axilar; $\mathrm{j}$ - osso esterno e inserções do músculo peitoral maior; $\mathrm{k}$ - processo xifoide; 1 - músculo serrátil anterior; $\mathrm{m}$ - margem costal com inserção dos músculos oblíquos do abdome; $\mathrm{n}$ - músculo reto do abdome; o - impressão da linha alba; $\mathrm{p}$ - crista ilíaca; $\mathrm{q}$ - músculo glúteo médio; $\mathrm{r}$ - músculo tensor da fáscia lata; $\mathrm{s}$ - quinto dedo em oposição; $\mathrm{t}$ - ventre dos músculos extensores; $\mathrm{u}$ - ventre dos músculos flexores; $\mathrm{v}$ - músculo deltoide; $\mathrm{x}$ - músculo bíceps braquial; $\mathrm{z}$ - região ocupada por vasos e nervos braquiais; aa - tendões dos músculos flexores; bb - tendões dos músculos fibulares; cc - maléolo lateral; dd - tendões dos músculos extensores dos dedos; ee - margem anterior da tíbia; ff - tendão do calcâneo; gg - maléolo medial; hh - arco medial do pé.
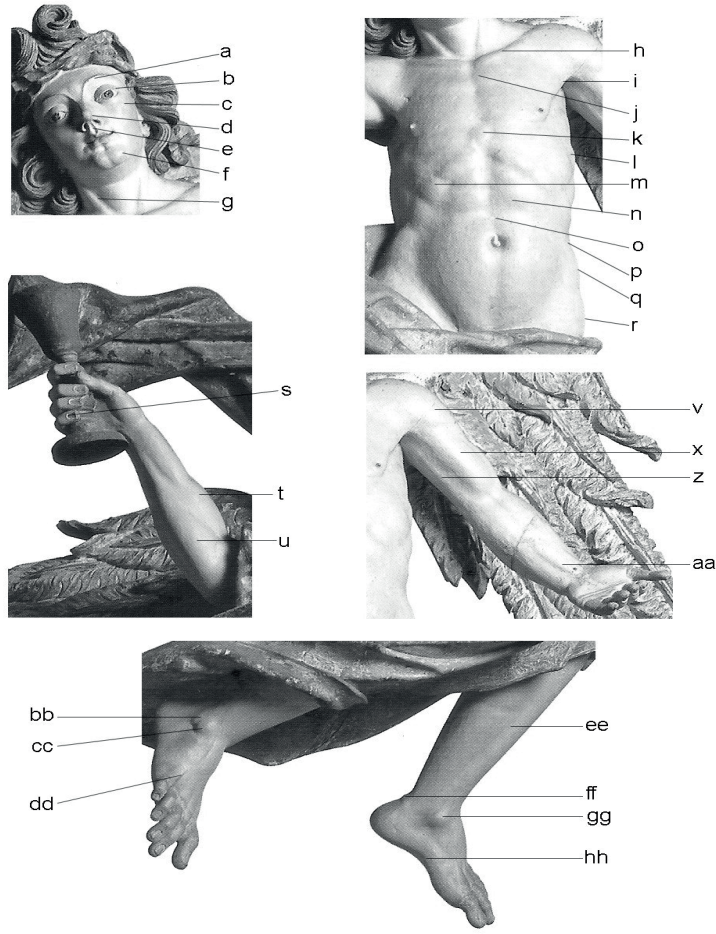


\section{DISCUSSÃO}

Em primeira instância constatamos uma incrível riqueza de detalhes corporais na obra analisada, além de admirável talento na forma da expressão corporal, característica do Barroco. As obras desse período são rebuscadas, detalhistas e expressam as emoções do homem, tendendo sempre a retratar a essência humana interpolada por caracteres divinos (LEMOS, 2008). Apesar da influência do Barroco europeu, o estilo no Brasil assumiu características particulares, tornando-se um dos períodos mais ricos e criativos da história brasileira (LEMOS, 2008). O Barroco evoca a religião em cada detalhe, como figuras de anjos e imagens revestidas de ouro. Santos são abundantes nas capelas, e os tetos geralmente representam um céu em perspectiva, aumentando a sensação de profundidade do ambiente (LEMOS, 2008). O estilo Barroco nasceu na Itália e vigorou entre os séculos XVI a XVII, e levou cerca de duzentos anos para chegar ao Brasil e, com isso agregou elementos de origens indígenas, dos paulistas, africanos escravos e portugueses. Os artistas formados em Portugal trouxeram conhecimentos religiosos dos livros sagrados e, antes a depois de Aleijadinho, os diferentes artistas e trabalhadores incorporaram elementos da cultura africana na arte barroca brasileira (LEMOS, 2008).

A obra "Anjo da Agonia" é conhecida, além dos motivos históricos e religiosos, pela opulência e exuberância de detalhes anatômicos. Essa riqueza anatômica é característica da fase Máxima de Aleijadinho, onde o artista apresentava maior domínio sobre as características morfológicas do corpo humano (JARDIM et al., 2011; IPHAN, 2016).

Analisando o acervo das obras do mestre Antônio Francisco Lisboa nota-se a existência de cinco fases produtivas. Seu estilo consiste em um conjunto de características do modo de fazer e elementos constantes. No total, são 28 estilemas que podem ser encontrados nas suas obras, especialmente nas esculturas. Entre os diversos estilemas observados no panejamento, destacam-se outros específicos da Anatomia Humana, como: "busca de perfeição anatômica, preciosismo de detalhes; nariz estreito, fino, longo e saliente, com narinas bem delineadas e profundas, asas nasais delimitadas na face por sulco pronunciado; malares (zigomáticos) altos e salientes; olhos amendoados, achinesados e mongolóides; hipertelorismo; sobrancelhas finas e arqueadas, em linha contínua com o nariz; 
pálpebras e supercílios bem separados e acentuados; boca entreaberta, lábios carnudos, em geral com dentes pequenos; pescoço forte, largo e anatomicamente perfeito; peito de sapateiro (pectusexcavatum), osso esterno inflexionado, depressão no tórax, porção pré-esternal em fúrcula aparente, presente apenas em algumas esculturas; má-implantação do polegar, bastante recuado e alongado, defeito aparente em grande parte das esculturas; artelhos dos pés longos; dedos médio $\left(3^{\circ}\right)$ e anular $\left(4^{\circ}\right)$ unidos" (JARDIM et al., 2011).

A primeira fase profissional de Aleijadinho (Mocidade, 17511760) foi caracterizada pelo primitivismo e presença de talento inventivo. Nessa fase as obras apresentavam anatomia imperfeita e desproporção. Na segunda fase (Maturidade Inicial, 1761-1770), já buscava a perfeição anatômica, apesar da dureza que desagrada à primeira vista. Na terceira fase (Maturidade Média, 1771-1780), atingiu a perfeição anatômica, com pleno domínio das regras de proporção. Na quarta fase (Maturidade Plena, 1781-1790) além da perfeição anatômica, o núcleo marcador dessa fase é o aspecto mundano da escultura sacra. Na quinta fase (Máxima, 1791-1812) as obras tinham caráter pomposo, solene, austero e místico. Foi na última fase na qual o Aleijadinho atingiu o máximo da perfeição anatômica, onde evidenciava detalhes de veias, músculos, tendões e os$\operatorname{sos}^{2}$. O "Anjo de Agonia" pertence ao conjunto de obras da fase Máxima.

$\mathrm{O}$ número de obras atribuídos à Aleijadinho tem gerado muita controvérsia, pois de uma relação com 141 obras estabelecidas pelo Instituto do Patrimônio Histórico e Artístico Nacional (Iphan) em 1951, passou-se a 425 em 2006. Muitos historiadores ficam intrigados pela questão da possibilidade ou impossibilidade da realização de tantas obras, contudo, Aleijadinho trabalhou, para seu sustento, por mais de 50 anos em uma oficina com diversos auxiliares e escravos. Outra razão é que boa parte de suas obras é constituída por esculturas pequenas (entre 20 e $40 \mathrm{~cm}$ ) e em madeira leve e macia, geralmente o cedro (JARDIM et al., 2011).

Mesmo para um grande artista plástico, construir durante a vida um número grande de obras depende, em muito, do conhecimento técnico e cultural desenvolvido durante anos de prática. A exposição ao corpo humano que o artista plástico é submetido acaba sendo uma importante fonte de observação e estudo da Anatomia Humana. As proporções, contornos, posições corporais e volumes são assimilados, observando modelos 
tridimensionais e naturais. Apesar das obras de Aleijadinho apresentarem dissonâncias anatômicas como olhos afastados e polegar desalinhado, o conjunto de sua obra mostra, claramente, seu domínio sobre o corpo humano. A fusão entre conhecimento anatômico e estilemas artísticos são blocos de conhecimento referentes a anatomia artística.

A anatomia artística é um dos fundamentos do artista figurativo ao lado do estudo das técnicas e da composição. Na face do "Anjo da Agonia" observamos uma série de detalhes anatômicos que expressam a intenção do artista na busca da perfeição. Uma face anatomicamente estética envolve a distribuição proporcional, harmônica e combinada de suas estruturas superficiais (MADEIRA, 2004). Enquanto a beleza é resultado de uma estética e de uma sã personalidade refletida. Apesar da simetria facial ser um critério que os artistas levam em consideração, anatomicamente não há face verdadeiramente simétrica. Existe uma assimetria normal, e os artistas estão cientes de que essa variação normal é necessária para dar vida e realismo às suas obras (MADEIRA, 2004). A representação artística do corpo humano presente no "Anjo da Agonia" é fiel a realidade física do corpo em movimento, em que podemos observar a tensão muscular no tronco e pescoço. A posição semipronada do antebraço direito e também a posição levemente inclinada superiormente da pelve direita mostram detalhes de movimentos articulares biomecanicamente corretos. O corpo despido, com tronco e membros expostos mostra a intenção do artista em expressar força física e vitalidade à sua obra.

Aproveitando o ensejo e visando à busca de uma renovação didática para o ensino de anatomia ambicionou se o uso de imagens de obras de Aleijadinho para o ensino de anatomia que, juntamente com outros fatores cruciais para o desempenho estudantil como a compreensão funcional de estruturas morfológicas e a rotina de estudos, tanto teórico quanto prático (VAVRUK, 2012), poderia tornar-se um aliado importante no aprendizado, de forma mais lúdica, do conteúdo. Os modernos métodos de ensinar anatomia vêm sendo estruturados com combinação de múltiplos recursos pedagógicos. Estudos mostram que estudantes aprendem mais eficientemente quando abordagens multimodais estão integradas (ESTAI et al., 2016). O uso de metodologia artística no ensino anatômico foi proposto por Da Silva et al. (2004), em que acadêmicos vivenciaram essa prática pedagógica inovadora, criativa e reflexiva. Da Silva et al. 
(2004) observou melhor aproveitamento acadêmico proporcionado pela metodologia artística, com uso de desenhos, modelagem e observação de peças anatômicas.

Um estudo realizado por Finn et al. (2010) mostrou que o uso de pintura corporal no ensino de anatomia, associado ao método tradicional, para estudantes de medicina mostrou ser um recurso lúdico, que tirou os estudantes de sua zona de conforto, favorecendo o aprendizado (FINN et al., 2010). O desafio é envolver os discentes através da elaboração de uma nova forma de abordagem desse conteúdo anatômico "inusitado". Eis que surge o posicionamento de uma renovação na modulação e forma de ensino e aprendizagem e, para tal vislumbra se a possibilidade de se usar dentro da Universidade Federal de Ouro Preto, que se encontra em um berço da cultura barroca de nosso país, obras de Aleijadinho para colaborar com os estudos acadêmicos de anatomia e congregar também um arcabouço cultural em estudos de anatomia.

Pode-se concluir que o mestre Aleijadinho dotava de profundos conhecimentos de Anatomia Humana, provavelmente não por meio de estudos nem formação orientada para a Anatomia Humana, mas através da observação de pessoas, corpos humanos, possivelmente de seu convívio social e profissional. Muito do que foi aprendido por Aleijadinho veio dos ensinamentos de seus mestres. Esses fatores corroboram com o talento nato de Aleijadinho, pois somente verdadeiros artistas apresentam o dom de observar o corpo e reproduzi-lo com perfeição em madeira, pedra ou pintura, enobrecendo ainda mais o talento de Antônio Francisco Lisboa. Também se constata a real possibilidade do uso da imagem do "Anjo da Agonia" como ferramenta metodológica no ensino de Anatomia Humana, visto que modernas estratégias pedagógicas recomendam o uso de intervenções multimodais.

\section{AGRADECIMENTOS}

Ao Senhor Agostinho Barroso de Oliveira, Diácono da Paróquia de Nossa Senhora da Conceição de Ouro Preto - MG, pelo suporte técnico e bibliográfico. 


\section{REFERÊNCIAS}

ESTAI, M.; BUNT, S. Best teaching practices in anatomy education: a critical review. Annals of Anatomy-Anatomischer Anzeiger. 2016.

FINN, G. M.; MCLACHLAN, J. C. A qualitative study of student responses to body painting. Anatomical sciences education, v. 3, n. 1, p. 33-38, 2010.

FRAHER, J. P.; EVANS, D. J. Training tomorrow's anatomists today: a partnership approach. Anatomical sciences education. v. 2, n. 3, p. 119-125, 2009.

IPHAN. Aleijadinho: Antônio Francisco Lisboa. Instituto do Patrimônio Histórico e Cultural Nacional. Disponível em: $<$ http://portal. iphan.gov.br/portal/montarPaginaInicial.do>. Acesso em:13 maio 2016.

JARDIM, M.; PINTO, H. S.; COIMBRA M. O Aleijadinho: catálogo geral da obra: inventário das coleções públicas e particulares. Itu: Igil, 2011. 326 p.

LEMOS, M. A. B.; ALVES, D. M. Aleijadinho: homem barroco, artista brasileiro. Rio de Janeiro: Garamond, 2008. 150 p.

MADEIRA, M. C. Anatomia da face: bases anatomofuncionais para a prática odontológica. 5. ed. São Paulo: Sarvier, 2004. 272 p.

MAIA, M. R. de C. Uma quinta portuguesa no interior do Brasil ou a saga do ilustrado Dom Frei Cipriano e o jardim do antigo palácio episcopal no final do século XVIII. História, Ciências, SaúdeManguinhos, v. 16, n. 4, p. 881-902, 2009.

MUSEU Aleijadinho. Disponível em: <http://www.museualeijadinho. com.br/index.php?op=home\&menuId=79>. Acesso em: 7 abr. 2016.

NETTER, F. H. Atlas de anatomia humana. 5. ed. Rio de Janeiro: Elsevier, 2011. 624 p. 
PONTINHA, C. M.; SOEIRO, C. A dissecação como ferramenta pedagógica no ensino da anatomia em Portugal. Interface-

Comunicação, Saúde, Educação, v. 18, n. 48, p. 165-176, 2014.

SILVA, R. A. da; GUIMARÃES, M. M. Arte educação: facilitando o ensino de morfologia. Educere - Revista da Educação da UNIPAR, v. 4, n. 1, p. 55-64, 2008.

SOBOTTA, J. Atlas de anatomia humana. 22. ed. Rio de Janeiro: Guanabara Koogan, 2012. 864 p.

TEIXEIRA, J. M. Aleijadinho: o teatro da fé. Ouro Preto: Espírito Santo Cultura, 2007. 188 p.

UNESCO. Disponível em: $<\mathrm{http}: / /$ whc.unesco.org/en/list/search=c ongonhas \&searchSites $=\&$ search_by_country $=\&$ region $=\&$ search yearinscribed $=\&$ themes $=\&$ criteria_restrication $=\&$ type $=\&$ media $=\&$ order =country\&description $>$. Acesso em: 29 maio 2016.

VAYRUK, J. A importância do estudo da anatomia humana para o estudante da área de saúde. O Anatomista, v. 3, n. 2, p. 4-35, 2012.

Recebido em: 27/10/2016 Aprovado em: 27/03/2017 